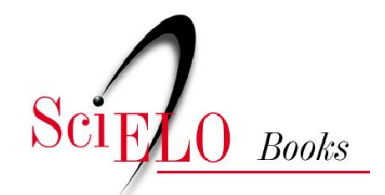

\title{
A metanarrativa em António Lobo Antunes
}

\author{
Rosângela de Melo Rodrigues
}

\section{SciELO Books / SciELO Livros / SciELO Libros}

RODRIGUES, RM. A metanarrativa em António Lobo Antunes. In: MEDEIROS, A., org. Travessias pela literatura portuguesa: estudos críticos de Saramago a Vieira [online]. Campina Grande:

EDUEPB, 2013, pp. 41-64. ISBN 9788578792794. Available from SciELO Books $<\underline{\text { http://books.scielo.org }>}$

\section{(c) $\frac{1}{\mathrm{BV}}(2)$ (2)}

All the contents of this work, except where otherwise noted, is licensed under a Creative Commons Attribution-Non Commercial-ShareAlike 3.0 Unported.

Todo o conteúdo deste trabalho, exceto quando houver ressalva, é publicado sob a licença Creative Commons Atribuição Uso Não Comercial - Partilha nos Mesmos Termos 3.0 Não adaptada.

Todo el contenido de esta obra, excepto donde se indique lo contrario, está bajo licencia de la licencia Creative Commons Reconocimento-NoComercial-CompartirIgual 3.0 Unported. 


\title{
A metanarrativa em António Lobo Antunes
}

\author{
Rosângela de Melo Rodrigues
}

Neste breve ensaio, propomos uma abordagem em paralelo dos romances Que cavalos são aqueles que fazem sombra no mar?, do escritor português António Lobo Antunes, publicado no Brasil pela Editora Objetiva, em 2009, e Os Cus de Judas, do mesmo autor, publicado aqui pela mesma editora, em 2007. Apontados pela crítica como romances que metaforizam a decadência dos valores morais, econômicos e culturais de tradicionais famílias portuguesas, além de situarem a perda da identidade e dos referenciais burgueses em indivíduos postos em situação de conflitos existenciais, esses livros estabelecem diálogos significativos também em torno da própria estruturação do gênero romanesco nesta primeira década do século XXI, e é nisto que centraremos o nosso foco analítico.

Sem os exageros retóricos de Fado Alexandrino e sem os inquietantes comprometimentos político-ideológicos de $\mathrm{Os}$ Cus dos Judas, Que cavalos são aqueles que fazem sombra no 
mar? foi recebido pelos leitores habituais de Lobo Antunes como um romance fácil, o que é um dado a mais para aguçar nossa eterna pergunta diante das obras do autor: afinal, qual armadilha desta vez, nos arma o Lobo?

Com a alegria de um reencontro esperado, o leitor volta a conviver nesta trama com a persona do escritor ficcional camuflado por trás da ficção, que também conduz a leitura de Memória de Elefante, Arquipélago da Memória e Conhecimento do Inferno. Em face da insistência com que tal personagem se presentifica na obra em tela, seria até mesmo irônica uma menção à instância do impied author, como o definiu W. Booth (1967). A trama deste romance gira em torno de um romance que está sendo escrito pelo próprio Lobo Antunes. Como um Hitchcock da literatura, o criador aqui passeia perfilado entre suas criaturas pondo, à mostra, algo que vai além da composição do retrato em preto e branco da decadente classe burguesa: a angústia de um autor resultante do processo de criação ficcional; criação não só no branco da página ou no da tela, mas no interior mesmo de seu aparelho psíquico no momento exato da fatura do texto, o que é muito mais expressivo do ponto de vista da técnica romanesca e da esfera da recepção.

Cada personagem de Que cavalos são aqueles que fazem sombra no mar? tem plena consciência de que é um mero ser de papel, uma criação ficcional. Apresentando-se ao leitor como ghost writer do escritor António Lobo Antunes (aqui, no interior da trama, também personagem ficcional), um por um vai compondo o que seria um memorial contendo a saga do Clã Marques. Narram à revelia, desordenados, inseguros, em estilo tosco e truncado, o passado e 
o presente de uma tradicional família portuguesa que tem dia e hora marcados para ser extinta: seis horas da tarde de um triste e chuvoso domingo de Páscoa, quando enfim a matriarca da família seria dada como morta. O presente da narração ocorre um mês após esta morte.

A narração dividida de modo igualitário entre muitos personagens tem sido, há décadas, estratégia empregada com o claro propósito de trazer para o centro da trama variadas versões de um mesmo enredo nítido e linear, com um fato central identificado como núcleo duro da trama, e variadas vozes competindo a disputa na preferência do leitor pela versão mais bem contada. Neste tipo de romance, a unidade tende a desaparecer para dar lugar à situação de polifonia.

Em Que cavalos são aqueles que fazem sombra no mar?, o percurso narrativo se diferencia do modelo acima descrito e chega, em certo sentido, a fazer o caminho inverso. Temos como narradores a mulher em seu leito de morte (que continua a narrar após a própria morte), seu esposo (também já falecido), sua meia-irmã e criada Mercília, os seus filhos Francisco, João, Ana, Beatriz, Rita (já falecida há anos) e o "bastardo que vive na quinta", destituído de visibilidade na trama, conhecido como o que não pode ser nomeado, mas que tem uma função primordial no enredo: é ele, a mando dos irmãos com quem nunca conviveu, o escolhido para assassinar a anciã, num ritual cristão primitivo cumprido no simbólico domingo pascoal. Com a morte da matriarca do clã Mendes, decreta-se também a morte do romance até então tecido.

Todos eles narram exatamente as mesmas ações internas e externas do enredo, e cada um, apropriando-se de um 
estilo coletivizado, é capaz de reproduzir com fidelidade extrema o que um outro personagem faz, sente, lembra e trama. Mais do que isto, eles narram mais para se ocultarem do autor do livro do que para se mostrarem aos leitores e por tal razão trocam de identidade narrativa diversas vezes: um irmão diz ser um outro, a mãe narra da situação comunicacional dos filhos, mortos narram como se estivessem vivos, vivos narram se passando por mortos, objetos e seres vegetais falam com vivos, adultos narram sob efeito de regressão de memória e se passam por crianças, fetos falam no ventre da mãe etc. A impressão comunicativa criada lembra uma peça na qual todos os personagens recebem por engano falas trocadas e algumas idênticas, $o$ que reforça a percepção de que as personagens do romance perderam todos os seus referenciais e se despersonalizam quanto mais falam. Elas não falam entre si: falam para si, como se estivessem em situação de análise, quando o muito falar mascara o silêncio entre simulacros de interlocutores; a propósito, cada capítulo do livro pode ser lido como um conto ou, do lado oposto, como um relato biográfico de pacientes a um médico psiquiatra. Pinceladas entre as falas das personagens estão também as do personagem Lobo Antunes, que com elas dialoga, disputa e com quem redige o texto, deixando-o cheio de rasuras, feito pistas para o leitor sobre quem manda narrar o quê ali.

A pluralidade e o confronto de vozes, pois, dá lugar de fato a uma voz unívoca, com propósitos que atendem ao eixo central da trama: a fatura do romance que o próprio Lobo Antunes escreve; disso resulta certo loosenes e o enredo emperrado que aproximam a obra do estilo pós-moderno de narrar, por um olhar meio enviesado 
e, também, por mais paradoxal que possa ser, do tipo de narrativa descrita por Walter Benjamim em seu famoso ensaio sobre a obra de Nikolai Leskov. O que vemos nesse romance tido por muitos como polifônico, portanto, são personagens que perderam não apenas o status de tradicional família e com ele os seus bens materiais e simbólicos, mas principalmente o que se perdeu nesse núcleo de seres atormentados pela nulidade existencial foi a capacidade de intercambiar experiências, daí a apropriação dos discursos uns dos outros e, principalmente, das experiências de vida. Sobre esse esvaziamento da matéria narrada nos diz Walter Benjamin:

A origem do romance é o indivíduo isolado, que não pode mais falar exemplarmente sobre suas preocupações mais importantes e que não recebe conselhos nem sabe dá-los. Escrever um romance significa, na descrição de uma vida humana, levar o incomensurável a seus últimos limites. (BENJAMIN, 1994, p. 201).

Que cavalos são aqueles que fazem sombra no mar? nos apresenta essa situação incomensurável em seu cerne. Uma anciã luta em seu leito de morte para permanecer viva até o final da tarde, enquanto seus filhos se esforçam em justificar, cada um ao seu modo, o prolongamento de suas próprias vidas, também com prazos rigorosamente estipulados para ter fim: eles vivem até o autor do livro decretar a morte de todos, pondo um ponto final na trama. Temos então um elenco de tristes personagens que narram, como Sherazade, para poder viver. 
Cientes da exiguidade de tempo, da precariedade das lembranças forjadas e das limitações discursivas, os personagens se desnudam e confessam suas mais obscuras verdades, imprecando e, às mais das vezes, tramando contra o escritor que os trata como reles ventríloquos. Semelhantes a pecadores num confessionário, a pacientes em um divã freudiano ou a simples esboços de um indeciso escritor, falam o que de fato viveram e o que sentem, ao mesmo tempo em que fantasiam e alucinam, passando da condição de personagens romanescos a de autores dos seus próprios dramas. Nesse cenário, pais, avós, bisavós, filhos, empregados, netos, amigos e amantes, uns já mortos e outros ainda vivos, meticulosamente traçados como personagens caricaturais, aproximam-se ao ponto de não haver quase limites entre eles: cada personagem é ele mesmo e todos os demais juntos, vivendo num presente perpétuo à espera das seis da tarde que parecem nunca chegar: o relógio congela o tempo e impede, como um anjo exterminador, a entrada da morte e do filho cujo nome não se diz, o carrasco que ceifará a vida da anciã.

A perda da identidade, como foi visto anteriormente, é a tônica da trama: os personagens vagam trocando de funções, de vozes, de lugares e de nomes; esse apagamento das individualidades reforça o caráter alegórico da obra, já apontado por alguns críticos como resultante da condição de insulamento e sensação de circularidade vivenciada em alguns períodos históricos pelo povo português. Essa troca de papéis também deriva da tentativa vã de erradicação de qualquer traço de culpa pelo assassinato da matriarca, um golpe duro tramado contra o próprio autor e seu livro: o 
que narrar após a morte daquela mãe que representa ali o nome/lugar do pai?

Em torno do simbólico corpo quase cadáver da anciã morta, todos falam muito, com discursos caóticos, marcados por muito rancor, tristes lembranças, autoacusações e confissões catárticas. Essa pluralidade de vozes narrativas provoca de modo invariável um antitético silenciamento discursivo; os personagens andam em círculo, fantasmagóricos e amedrontados: cada um monologa com seus botões como quem repassa um texto a ser encenado. É sintomático como, reiteradas vezes, há referências à perda da sombra, da voz e da consciência de existir: "Quase tudo se passa em silêncio na vida, mesmo os gritos" (ANTUNES, 2009, p. 25). Beatriz, a filha mais velha, via cavalos fazendo sombra no mar; ela e seus irmãos, como de resto todo o clã, de tão perdidos em suas vidas inúteis, não chegam mesmo a ter direito a uma sombra, aqui marca do que é livre, do que vive sob o sol, mas também, pelo avesso, do demoníaco e do espectral. Assim se expressa João, o que vivia sob as sombras das árvores num ponto de prostituição:

[...] quem me lembrará um dia, o que será de mim na memória dos outros, o maricas que tinha a doença a doença a doença a doença e envergonhava a gente, não montava cavalos que faziam sombra no mar, nunca fez sombra o pobre, o quarto dele sem móveis e meu irmão Francisco a trazer a creolina

- Desinfectem tudo isso.

(ANTUNES, 2009, p. 64). 
Se narram para poder existir, os personagens desta trama também burlam as regras impostas pelo deus tirano, onisciente e inalcançável, escondido por trás da personagem por trás do livro, como se constata na fala de Beatriz:

[...] não esclareço isso bem porque as palavras avançam depressa e o papel não chega, eis o António Lobo Antunes a saltar frases não logrando acompanhar-me e a afogar num tanque os gatinhos do que sinto para se desembaraçar de mim... (ANTUNES, 2009, p.17).

Nesta leitura que se impõe ao leitor, mais do que uma alegoria à derrocada das crenças, costumes e status da burguesia portuguesa, o romance traz, à baila, como tema crucial a própria constituição do escritor enquanto dono absoluto dos seus enredos, frases e efeitos. Ao longo da narrativa, na qual as ações emperram como ponteiros quebrados de um barulhento relógio antigo, paulatinamente o leitor acompanha a dramática tomada de consciência das personagens escravas do autor da obra que eles escrevem e contra quem vão se rebelando. Disso, resulta o silêncio das vozes e o embaralhar dos papéis e dos discursos. Como somos avisados na página 115 da obra, este é um "romance de espectros" em que seres ficcionais decretam a morte simbólica do autor que os trouxe à luz. Nessa rebelião das criaturas contra o criador, há produção de falas construídas com o propósito claro de ludibriar aquele que ocupa o lacaniano espaço do nome do pai: "Chamo-me João, chamo-me Ana” (ANTUNES, 2009, p. 125). "Na altura em que o livro for lido estarei onde ninguém me encontra". (ANTUNES, 
2009, p. 120). "Não foi nada de facto, é um livro e eu uma criatura do livro, não uma pessoa a sério, tranqüiliza-te que apenas vives se o compram" (ANTUNES, 2009, p. 125).

Essa percepção da obra como metaliterária põe em crise as críticas feitas por leitores menos afeitos à produção de Lobo Antunes que não conseguem avançar na leitura do romance em razão da excessiva (e por vezes irritante) repetição de frases. À medida que o quase inexistente enredo avança, ainda que a passos trôpegos, todos os personagens têm as mesmas falas, como numa cena buñueliana e surrealista na qual as mesmas rubricas são encenadas ad infinitum por todos os atores. Insubordinados, os personagens tramam, às escondidas, contra o autor e usam de chantagens, bajulações e simulacros na composição de seus discursos. Na cena em que o segredo da octogenária empregada Mercília está para ser revelado, quando finalmente ela poderia assumir ser filha bastarda do mais importante antepassado da família Marques, é possível ver esse jogo no qual um fato é mostrado e camuflado ao mesmo tempo. Mercília: a criada que herdou o nariz dos Marques, só admite falar caso ganhe vida e seja retirada de sua condição de personagem romanesca:

- Conheceste o bisavô Marques Mercília?

E uma vacilação, um espasmozito do corpo (isso é um livro ou não é um livro, se não é um livro falo)

Uma prega no nariz dos Marques (não é um livro, falo).

(ANTUNES, 2009, p. 126). 
É ainda a criada Marcília, ostentando o nariz da falsa nobreza e da condição bastarda, quem trava um embate num diálogo ácido e truncado com o seu criador, Lobo Antunes, numa escrita a quatro mãos:

... e se o António Lobo Antunes batesse isso no computador carregava em teclas ao acaso, não importa quais, até ao fim da página, letras, números, vírgulas, traços, cruzes, com vontade de encostar por seu turno a cara a mim, tapar os ouvidos, não continuar o livro e permanecer de ouvidos tapados não dando pela chuva nem pelo meu pai de regresso à vila comigo (como esta casa é triste às três horas da tarde)

com cinco ou seis anos

(cinco anos e oito meses)

a trotar ao seu lado, o fontanário, o largo, o palacete do comendador Cardoso sem janelas

(a sobrinha do comendador Cardoso num asilo a morder-se e a gritar)

O António Lobo Antunes esperando que as cheias do Tejo nos cobrisse a todos, sem ânimo de ler estas frases, o menino Francisco ultrapassou-me no corredor

- Seu estorvo.

(ANTUNES, 2009, p.148,149 - grifos nossos).

O desejo de morte ao pai fica evidente com mais visibilidade nas falas dos irmãos Ana e João, que brincam na trama de trocas de identidades e papéis. Ana, a louca, a ladra, a viciada em drogas, abusada sexualmente, na infância, por um pedófilo asqueroso e querido da família, filha renegada 
pela mãe ao nascer por ter trazido ao mundo a prova da infidelidade materna indicada na ausência, de imediato percebida, mas também por vezes afirmada na trama, do nariz dos Marques; João, o afeminado, o que se recusa a crescer e o mais amado pela mãe até se revelar homossexual, pedófilo, carente de afetos e soro-positivo. É ele quem também desafia o autor, num diálogo interessante, a não matar seus personagens, adiando o término do livro:

\section{- Para que prestas tu?}

e sei lá para que presto; como abomino o que escrevo, olha as vacas alinhadas no estábulo mastigando silêncio, engolem e mastigam de novo, contraria-me que as seis cheguem, preferia que ficássemos todos e o que faz este a almoçar conosco - Apetece-lhe almoçar com a gentinha que inventou?

(ANTUNES, 2009, p. 121)

Em outro trecho, os papéis se invertem, e o personagem Lobo Antunes passa a ser dominado na fatura do romance por suas criaturas:

O António Lobo Antunes

- Escrevo assim?

E eu

- Escreva

Porque se escrever assim não preciso de parques, dou com os cavalos que fazem sombra no mar e o meu pai com eles, ninguém morre pois não, estamos vivos, estou vivo

- Continua vivo que teima.

(ANTUNES, 2009, p. 123, 124) 
Nesse jogo da verdade, só há trapaças: personagens escrevem sob falsos nomes, camuflam acontecimentos, trocam de identidade no meio de uma fala, contam um mesmo fato com incríveis variações em cada versão, mentem e debocham do autor do romance, com o intuito de adiarem a morte da matriarca, metáfora da obra em confecção; enquanto o relógio não marcar as seis horas da tarde, $o$ ponto final não será posto.

e por conseguinte como se acaba o capítulo, estou no corredor a caminho do quarto e a chuva mais forte, amanhã um tijolo a faltar na chaminé e os toiros sob as azinheiras num cacho infeliz, podia terminar neste parágrafo e não termino, prossigo mesmo que tentem impedir-me prossigo, não morro, quanto mais me desejarem a morte eu mais vivo onde não sabem quem sou nem se importam comigo, um senhor na mercearia em que mal se repara e se perde em seguida sem fazer sombra em parte alguma

- Que senhor é aquele que não faz sombra em parte alguma?

(ANTUNES, 2009, p. 102)

Rita, a defunta autora aos moldes machadianos, a que passou a vida, à janela, falando com a lua, criou para si duas personalidades com existências independentes responsáveis por duas vozes na trama: era Laura e era Rita ao mesmo tempo, como era morta em vida (em semicoma, mantinha a consciência e mentia sobre o fato, o que provocou a opção familiar por uma eutanásia indisfarçavelmente desejada), vivia mais ativa no pós-morte. É dela a constatação da causa maior da 
desagregação da família e do extermínio dos membros do clã: a falta de ternura, o desamor e o insulamento emocional ("minha irmã Ana não chora, meu irmão Francisco não chora, não nos ensinaram a compreender a morte"). Mesmo após a morte, Rita procura o pai e não o encontra, ele que em vida também não passava de um espectro.

Francisco queria para si uma família digna e acusa Lobo Antunes de desonesto e egoísta. Ele queria uma família sem uma mãe conversando com a amante ao telefone ou trancada com a mulher amada num quarto da casa; sem um irmão buscando garotos na cumplicidade da noite; sem uma irmã trocando todos os objetos de valor da família por drogas no baldio. Zangado, ele implora a Lobo Antunes mais meia hora, antes que tudo acabe (ANTUNES, 2009, p. 216).

Ana, a que tem vergonha do que precisa escrever sobre si mesma, e pede: "[...] você que escreve o livro conte a história por mim" (ANTUNES, 2009, p. 289). Ela trava uma batalha com o autor e transfere, para ele, a relação distanciada e conflituosa que tinha com o pai e com a mãe, como vemos nesse falso monólogo (há um diálogo com Antunes, que interfere) em que a voz dele se mistura com a do pai ou com a da mãe mortos:

- Não me entendo com a Ana e de cada vez que me obriga a falar a minha voz foge-lhe, no cemitério abandonado um arcanjo de gesso à deriva nos caniços, o que se me afigurou um ancinho, o que se me afigurou uma enxada, ferramentas de vivos entre os pertences dos mortos e quem está vivo e quem está morto esclareça-me, não me entendo com a Ana, vou rasurá-la 
do livro e não me rasure do livro, se me rasurar do livro nunca fui

- Não a devia ter posto aqui, desequilibra-me o trabalho,

mas mesmo não sabendo o que fazer com ela não a mande embora, repito que ao acordar a meio da noite ensurdecida

(quando fala por mim detesta o que escreve?)

(ANTUNES, 2009, p. 292).

Ana - a esquizofrênica que quando criança ouvia vozes de árvores, do relógio, do espelho gritando o nome dela a noite inteira, e que na vida adulta alucina deliberadamente sob efeito de drogas, e a que reconhece o nariz dos Marques em um travesti no baldio - não aceita o papel que a ela cabe na trama:

[...] há por aí alguém com um resto de compaixão que acabe o meu discurso por mim eu que mal existo no livro, uma dúzia de frases que o António Lobo Antunes aprove e de que não sou capaz.

(ANTUNES, 2009, p. 207).

e que maçada ter de escrever esse livro, dava de boa vontade o meu lugar a outro, falem por mim, tomem, enquanto procuro aperceber-me do silêncio porque tanto ruído na minha cabeça, passos para onde e de quem e sobretudo o mecanismo da minha vida que não pára de andar...

(ANTUNES, 2009, p. 173). 
Ana se esquece várias vezes do próprio nome e é apresentada também como Micaela, Alice, João, Mercília e Beatriz. É dela a fala que decreta a morte do autor:

porque o mundo não se incomoda com a gente senhora nem com a gota que tomba de cada vez que um

- Por quê?

numa parte da minha mãe que nem estou certa que exista, o que sobeja quando não existimos, em que pensarei eu, este livro é o teu testamento António Lobo Antunes, não embelezes, não inventes, o teu último livro, o que amarelece por aí quando não existires, como esta casa é triste às três horas da tarde...(ANTUNES, 2009, p. 108, grifos nossos).

Este fato acontece com todos os personagens da trama que, por serem de papel, não conseguem fazer sombra no mar, como os cavalos. Da fala de Francisco, o que ouvia os demais personagens pensando, o "menino que não tinha alma", o que nasceu sem o nariz dos Marques ('Terei tido esse filho"? pergunta a mãe ao autor) retiramos os trechos:

Tomara que fossem seis horas e eu liberto do que escreve o livro atrás de nós a cheirar, qualquer criatura séria que se dê ao trabalho de uma vista de olhos no que fez até hoje compreende logo as mentiras, a minha irmã Ana isso, o meu irmão João aquilo, a minha irmã Beatriz ocupando-se da minha mãe e falso...

(ANTUNES, 2009, p.212)

... chegando ao final deste capítulo evaporo-me

(ANTUNES, 2009, p. 272). 
A matriarca acusa Lobo Antunes de cercear informações que ela deseja colocar no livro: "Comprovem se já mencionei a quinta, mal acabo uma página roubam-na" (ANTUNES, 2009, p. 301). Ela, por vezes, questiona o autor sobre o modo correto de narrar e joga para o leitor questionamentos sobre o ofício dele:

- Como se trabalha isso?

E quantas palavras são precisas para construir uma vida, não a nossa que só existimos ao lerem-nos, a dele. (ANTUNES, 2009, p. 301).

Para Foucault, esse autor por trás do autor é sintomático de um determinado espaço-tempo discursivo:

O autor (ou função do autor) é apenas uma das especificações possíveis da função sujeito. Numa sociedade em que os discursos circulassem no "anonimato do murmúrio", deixaríamos de ouvir questões por tanto tempo repetidas, como: 'quem é que falou realmente? Foi ele mesmo e não outro?' Pouco mais se ouviria do que o rumor de uma indiferença: 'que importa quem fala?.' (FOUCAULT, 1992).

Morte de Deus, morte do autor, morte do desgastado gênero romanesco ou da velha burguesia lusa são alegorias possíveis presentes neste inquietante romance de Lobo Antunes, que nos lembra insistentemente da certeza da finitude humana e da inutilidade de querer iludir a morte: morreremos como morrem os livros e as criaturas neles encadernadas. Deus não aceita barganhas. 
Se em Que cavalos são aqueles que fazem sombra no mar?, temos como pano de fundo a extinção das tradicionais famílias portuguesas num núcleo dramático composto por dezenas de personagens narradores, em Os Cus de Judas, o mais aclamado livro de Lobo Antunes, o processo é inverso, embora as motivações ideológicas se mantenham as mesmas. Em um ponto, no entanto, os narradores dos dois romances se assemelham: narram devido à necessidade visceral de continuar vivendo e sentem pavor diante da morte anunciada; não a física, mas a morte na matéria ficcional.

A trama em Os Cus de Judas apresenta um narrador desolado, imerso em uma solidão implacável e consciente da irreversibilidade do fato de ter ido ao inferno e de lá retornado outro. A exemplo dos membros do clã Mendes, este narrador tem uma percepção um tanto distorcida de sua própria classe, que vai sendo apresentada em sua faceta mais torpe a cada fato vivido e narrado, deixando à mostra um eu esfacelado e uma identidade cultural e ideológica cambiantes.

Nos dois romances aqui confrontados, a proximidade da morte provoca nos personagens a vontade imperiosa de elaborar 'testamentos emotivos'. Se em Que cavalos são aqueles que fazem sombra no mar?, o romance se fragmenta em contos que são reescritos diversas vezes na obra, com narradores diversos, em Os Cus de Judas, há uma estrutura mais próxima do memorial e do diário.

Nas duas obras o tratamento dado às vozes que narram se distinguem radicalmente. Como vimos, em Que cavalos são aqueles que fazem sombra no mar?, há uma aparente 
polifonia que se esvai numa leitura mais verticalizada para dar lugar a uma voz única, autoritária e autoral: a do escritor por quem e para quem os personagens falam. Em Os Cus de Judas a voz também é posta como armadilha para o leitor, que numa leitura mais apressada a identifica logo como sendo de um sujeito singular, que narra suas experiências pessoais e intransferíveis.

Médico militar, tendo vivido os horrores da guerra em Angola, no conflito no qual esteve em jogo a independência da colônia, o narrador se purga na volta ao seu solo histórico produzindo um relato catártico, que em muito se assemelha ao modo de narrar dos Marques: cheio de analepses, de falsas lembranças, de buracos existenciais; tautológico, às vezes beirando o delírio insano. Não por acaso, o médico, quase que permanentemente embriagado, alcança maior grau de lucidez quando ingere mais álcool. Como Ana, este médico usa a droga para ter coragem de narrar e ser fiel aos fatos surreais que viveu. Nos dois romances aqui confrontados, é a certeza da morte que põe, em crise, a linha tênue que separa realidade de ficção, fato vivido e fato imaginado, a arte e a vida. Sobre tal questão arquetípica e irremovível dos seres humanos e das pessoas de papel, fala-nos Walter Benjamin:

[...] é no momento da morte que o saber e a sabedoria do homem e sobretudo sua existência vivida - e dessa substância a que são feitas as histórias - assumem pela primeira vez uma forma transmissível. Assim como no interior do agonizante desfilam inúmeras imagens - visões de si mesmo, nas quais ele se havia encontrado sem se dar conta disso -, assim o 
inesquecível aflora de repente em seus gestos e olhares, conferindo a tudo o que lhe diz respeito aquela autoridade que mesmo um pobre-diabo possui ao morrer, para os vivos em seu redor. $\mathrm{Na}$ origem da narrativa está essa autoridade. (BENJAMIN, 1994, p. 208).

O narrador de Os Cus de Judas, de imediato, lembra os fatos vividos e quer falar sobre eles, mas, como seus pares de Que cavalos são aqueles que fazem sobra no mar?, ele esqueceu como se narra, como se transforma matéria vivida em matéria narrada. Volta da guerra silenciado, sem exemplos a dar, sem conselhos a receber, sem pátria, sem família, sem lugar para estar no mundo. Como o narrador descrito por Benjamin, este também perdeu a capacidade de intercambiar experiências e por mais que fale é outro que fala por ele, e sua existência, ao fim e ao cabo, vale tanto ou menos que a de qualquer outro personagem ficcional, inclusive o que ocupa as instâncias de autor e de leitor, também simulacros de pessoas reais a exercerem os papéis que lhes cabem:

[...] o leitor do romance procura realmente homens nos quais possa ler "o sentido da vida". Ele precisa, portanto, estar seguro de antemão, de um modo ou de outro, de que participará de sua morte. Se necessário, a morte no sentido figurado: o fim do romance. (...) o que seduz o leitor no romance é a esperança de aquecer sua vida gelada com a morte descrita no livro. (BENJAMIN, 1994, p. 214). 
Se em Que cavalos são aqueles que fazem sombra no mar?, o autor estabelece um pacto com o leitor, esclarecendo inúmeras vezes que aqueles seres são personagens que desejam se insurgir para deixar de serem pessoas ficcionais, em $O s$ Cus de Judas, num processo inverso, um narrador, ciente de sua existência como um misto de médico e soldado (monstro) de guerra, luta para apagar lembranças da memória e criar para si uma outra vida, talvez mais bucólica, talvez até espiritual, como se pudesse rasurar o passado terrível que viveu e o presente sem sentido e criar para si um papel como personagem ficcional.

Nesta busca pelo apagamento de uma existência marcada pelos horrores da guerra, pela impotência de médico em campo de batalha e pela dissolução de personalidade sentida no retorno, é no álcool e na arte que o narrador tenta achar a brecha que o transportará do plano da realidade para o plano da ficção. As insistentes referências a pessoas importantes da alta cultura, que poderiam parecer exibicionismo infantilizado do autor ou do personagem médico, no interior da narrativa funcionam como válvula de escape: é com a arte, com sua incursão no sublime, que o narrador pode se elevar da lama onde ele se perdeu dele mesmo.

Modigliani, Bosch, Vieira da Silva e Matisse são alguns nomes evocados na pintura. Fernando Pessoa, Bocage, Lewis Carrol, P. Éluard, Goeth, António Nobre, Máximo Gorki, Camões, Hemingway e Tomás Ribeiro são alguns dos muitos autores citados no campo da literatura. Uma letra de canção de Paul Simon é lembrada na íntegra pelo narrador, que na música também cita Bob Dylan e John 
Coltrane. Do cinema, ele evoca Humphrey Bogart, Lauren Bacall, Chaplin e Audrey Hepburn. Além desses personagens que dão suporte cultural e identitário ao narrador, ele fala em Freud, Guevara, Al Capone, Voltaire, Reich, que aparecem na obra muito mais como elementos de construção de um cenário sócio-histórico do que por seus méritos individuais.

O plano ressaltado aqui é o coletivo: o narrador, isolado em seus próprios dramas, quer se integrar a algo que o distancie da guerra e se vale do cabedal de cultura que tem para dar a si próprio o bálsamo do pertencimento, da sensação de estar partilhando informações estéticas que são de conhecimento massificado. Ele recorre à arte para dizer ao mundo: existo porque vi essa tela que você viu; li o livro que você leu e sei decorada a canção que toca nas rádios. $\mathrm{O}$ sentimento de estar ligado (ou religado) chega a ser místico e ele se purifica nesse processo enquanto corpo coletivo. O que ele quer é se integrar, ainda que via plano da irrealidade, ainda que como objeto ficcional.

O encanto dos bares, não é, consiste em, a partir das duas da manhã, não ser a alma a libertar-se do seu invólucro terrestre e a seguir verticalmente para o céu no esvoaçar místico de cortinas brancas das mortes do missal, mas a carne que se livra, um pouco espantada, do espírito, e inicia uma dança pastosa de estátua de cera que se funde até terminar nas lágrimas de remorso da aurora, quando a primeira luz oblíqua nos revela, com implacabilidade radioscópica, o triste esqueleto da solidão sem remédio (ANTUNES, 2007, p.43). 
Esse narrador não quer matar a mãe que ocupa o lugar do pai/autor como em Que cavalos são aqueles que fazem sobra no mar?; o que ele busca é matar no seu passado o que ele foi, o que viu e o que fez.

Porque camandro é que não se fala nisto? Começo a pensar que o milhão e quinhentos mil homens que passaram por África não existiram nunca e lhe estou contando uma espécie de romance de mau gosto impossível de acreditar, uma história inventada com que a comovo a fim de conseguir mais depressa (um terço de paleio, um terço de álcool, um terço de ternura, sabe como é?). (ANTUNES, 2007, p.65).

Só reencontrando a pessoa que foi antes da guerra, seus laços afetivos, suas referências políticas e culturais, ele será capaz de romper o silêncio do soldado que volta da guerra, para falar outra vez e exercer o direito de interagir, de comunicar.

[...] a ânsia de escrever e o torturante pânico de não ser capaz, de não lograr traduzir em palavras o que me apetecia berrar aos ouvidos dos outros e que era Estou aqui, Reparem em mim que estou aqui, oiçam-me até no meu silêncio e compreendam, mas não se pode compreender... (ANTUNES, 2007, p.153).

É contra o silêncio dos vencidos que ele fala. Como explica Walter Benjamin, "A morte é a sanção de tudo o que o narrador pode contar. É da morte que ele deriva sua autoridade" (BENJAMIN, 1994, p. 208). 
Esse narrador, à semelhança dos personagens de Que cavalos são aqueles que fazem sombra no mar?, é escritor e faz questão de, reiteradas vezes, afirmar esta condição, sem a qual não haveria razão para existir: "Os romances por escrever acumulavam-se-me no sótão da cabeça à maneira de aparelhos antiquados reduzidos a um amontoados de peças díspares que eu não lograria reunir" (ANTUNES, 2007, p. 51).

Esse tema, ou, melhor dizendo, este modo de narrar não se restringe aos dois livros aqui abordados. Num de seus romances mais cruéis, o recém-lançado $O$ Arquipélago da insónia, no qual se tece uma trama tendo como pano de fundo o autismo, os narradores também têm consciência da dupla existência como personagens autônomas e como autômatas, e, em certa altura do livro, uma delas que assume função narrativa diz "[...] foi o meu irmão que escreveu essas páginas muito mais devagar do que se passou de facto, não fui eu quem o disse" (ANTUNES, 2010, p 98). Noutra passagem achamos: "(que espécie de livro é este que custa tanto escrever?)" (ANTUNES, 2010, p.165). Ainda em $O$ Arquipélago da insónia temos uma personagem que sintetiza todas as que aqui foram citadas como tendo a vida longa ou finda, a depender das vontades de um autor/deus. Hortelinda, uma mulher temida por todos por "fazer o serviço de Deus quando ele estava sem querer ou poder trabalhar", tem o poder de matar uma pessoa ou deixá-la viver apenas riscando ou não um nome num livro imaginário; ela, pois, resume em si a metáfora da criação divina e romanesca, a vida ficcional ou ao rés-do-chão. 
Matricidas, pedófilos, drogados, autistas, aidéticos, profetas, loucos e uma série enorme de seres de exceção, rejeitados, invisíveis e inaudíveis são seres ficcionais que, nas tramas de Lobo Antunes, irremediavelmente se mesclam à figura do autor, ao seu país de origem e ao modo fragmentado do narrar pós-moderno. Além de colocar, no tabuleiro narrativo, a derrocada econômica, identitária e cultural da burguesia portuguesa, Lobo Antunes redimensiona o próprio conceito de literariedade e se firma hoje como o mais criativo escritor de língua portuguesa.

\section{Referências}

ANTUNES, António Lobo. O Arquipélago da insónia. Rio de Janeiro: Objetiva, 2010.

. Que cavalos são aqueles que fazem sombra no

mar?. Rio de Janeiro: Objetiva, 2009.

. Os Cus de Judas. Rio de Janeiro: Objetiva, 2007.

BENJAMIN, Walter. Obras escolhidas: magia e técnica, arte e política. São Paulo: Brasiliense, 1994.

BOOTH, Wayne C. The Rhetoric of Fiction. The University of Chicago Press: Phoenix Books, 1967.

FOUCAULT, M. O que é um autor?. Porto: Vega, 1992. 